Review Article

\title{
Pharmacological potential of wood apple (Limonia acidissima): A Review
}

\author{
G.M. Masud Parvez* and Ranjan Kumar Sarker \\ Department of Pharmacy, Pabna University of Science and Technology, Pabna 6600, Bangladesh. \\ *Email: masud.ph.ru@gmail.com,masud.ph@pust.ac.bd \\ Received: 20.04.2021 ; Revised: 25.06.2021 ; Accepted: 28.06.2021
}

\begin{abstract}
Wood apple is an edible fruit of Rutacae family with less exploitation. The fruit pulp is edible and used in many food preparations around the globe. It is also used long time as traditional medicines. This review aimed to summarize the pharmacological potentials of this fruit. This fruit is effective against some deadly disease such as cancer, diabetes, hyperlipidemia and microbial infection. It also has capability to treat diarrhea, ulcer, and pain. Both ripe and unripe fruit has strong pharmacological activity. The presence of phenolic and flavonoids are the main antioxidant responsible for the therapeutic potentials.
\end{abstract}

Keywords: Antimicrobial, cancer, diabetes, pharmacological activity, wood apple

\section{INTRODUCTION}

Plants are one of the major source traditional medicines which have been used more than thousands of years ago. Natural plant based products has already gaining popularity because of its low side effects and its popularity is rising with widening range of applications from pharmaceuticals to cosmetics. The Medicinal \& Aromatic Plants are main sources of different phytochemicals - alkaloids, phenolics, saponins, steroid, flavinoids, glucoside, terpenoids, tannins, aliphatic alcohols, acids and esters, etc. and essential oils with a wide variety of applications in pharmaceuticals, flavours and fragrance, disinfectants, oral hygiene and in almost all spheres of human activity (Sarwar, 2020). The fruit wood apple (Limonia acissimia $\mathrm{L}$ ) belongs to the family of Rutaceae and is found in India, Pakistan, Bangladesh, Sri Lanka and Southeast Asian countries (Rodrigures et al., 2018; Hiwale, 2015). The fruit resembles an apple which leads to the establishments of the name. The peculiar fruit wood apple looks like a rotten coconut on the shell while in the inside it has soft pulp. The fruit smells like mixed stench of rotten blue cheese with overripe bananas. Wood apple pulp has sour and funky taste which is delicious with touch of sugar in desserts or with warm spices for savory dishes. The fruit is a remedy for cancer, diabetes, diarrhea, ulcer, and blood pressure. Regular consumption of this fruit helps to prevent from these disease.

\section{PHYTOCHEMICALS AND NUTRIENTS}

Wood apple contains phytochemicals like polyphenols, vitamins, saponins, coumarins, amino acids, tri-terpenoids, phytosterols and tannins (Pandey et al., 2014). Phytochemical analysis of Limonia acidissima ripe fruits indicates presence of flavonoids, steroids, glycosides and various acidic compounds. The major chemical compounds in leaf are acidissimin and acidissiminol. Presence of alkaloids, phenolsresins, gum and mucilage, fixed oils and fats are also noted in leafs (Aneesha et al., 2018; Panda et al., 2013; Jayashree and Londonkar, 2014 and Vijayvargia et al., 2014).The wood apple pulp is very good source of carbohydrates $(70.14 \%)$, protein $(13.8 \%)$, fat $(4,3 \%)$ and dietary fibre (1.7\%) (Pandey et al., 2014; Asp, 1996). Presence of low amount of fat (4.38\%), calcium, magnesium, iron, and high amounts of zinc are also reported in this fruit. High amount of phosphorous and calcium are also found out that exerts vital role in bone formation, blood clotting and more other metabolic processes (Table $1)$. The presence of iron in fruit indicates effectiveness against anemia, tuberculosis and other disorders (Campous et al., 2009).

\section{ETHNOMEDICINAL USES}

Various parts of wood apple have been used for more than thousands of years in traditional medicines. Both ripe and unripe fruits have reputation for its medicinal properties. The phytochemical and minerals are responsible for 
Table 1: Mineral and Vitamins content of kaitha pulp (Pandey et al., 2014)

\begin{tabular}{|c|c|c|c|}
\hline \multicolumn{5}{|c|}{ Minerals (ig/g) } \\
\hline Analyte & Concentration(ig/g) & Analyte & Concentration(ìg/g) \\
\hline $\mathrm{P}$ & 1137.35 & $\mathrm{Cr}$ & 1.543 \\
\hline $\mathrm{Mg}$ & 852.5 & $\mathrm{~Pb}$ & 0.163 \\
\hline $\mathrm{Ca}$ & 711.8 & $\mathrm{Li}$ & 0.241 \\
\hline $\mathrm{Fe}$ & 23 & $\mathrm{Mo}$ & 0.263 \\
\hline $\mathrm{Zn}$ & 23.84 & $\mathrm{Ni}$ & 0.819 \\
\hline $\mathrm{Cu}$ & 6.67 & $\mathrm{Se}$ & 0.768 \\
\hline $\mathrm{Mn}$ & 3.64 & $\mathrm{Ti}$ & 0.257 \\
\hline \multicolumn{5}{|c|}{ Vitamins(ìg/g) } \\
\hline Vitamin $\mathrm{C}$ & 180 & Thiamine $\left(\mathrm{B}_{1}\right)$ & 0.31 \\
\hline Riboflavin $\left(\mathrm{B}_{2}\right)$ & 0.23 & Beta-carotene & 0.04 \\
\hline
\end{tabular}

providing therapeutic roles. In traditional system it is used to cure dysentery, diarrhea, asthma, wounds, tumors, hepatitis and cardiac debility. Ripe fruit also cure liver disease and heart problems. It has role on lowering cholesterol levels in blood (Vidhya and Narain, 2011 and Mishra and Garg, 2011). Juice of wood apple $(50 \mathrm{mg} / \mathrm{L})$ with warm water and sugar is recommended for detoxification via blood purification and removal of toxins from the body (Vasant and Narasimhacharyaa, 2011). In children, juice of wood apple leaves mixed with milk and sugar is given for the remedy of biliousness and intestinal problems. The essential oil of crushed leaves is used to cure itching and improves digestion problem (Morton, 1987). Wood apple leaves contains high amounts of tannins which is effective against peptic ulcer. The leaves are also effective in the treatment of breast cancer, uterus cancer, infertility, progesterone deficiency, flu and respiratory disorders (Jayakumar and Geetha, 2012). The leaves have traditional use in snake bites and against bacterial pathogens (Kirtikar and Basu, 1995). Astringent, carminative and hepatoprotective activity are also known for leaves (Ilango and Chitra 2009). The pulp has low fat content $(4.38 \%)$ and is an effective diet for overweight people (Pandey et al., 2014). The fruits are refrigerant, stomachic, stimulant, diuretic, astringent, aphrodisiac, cardiac tonic, liver tonic, anti-asthmatic, antidiarrheal, leucorrhoeal and also effective against dysentery. The seeds are used in the treatment of heart diseases (Jadeja et al., 2005; Senthilkumar et al., 2010). Spine of the tree is a remedy of menorrhagia. The bark contains $0.016 \%$ marmesin, aurapten, bergapten and other coumarins and is applied on venomous wounds upon crushing (Morton, 1987). The gum has demulcent, constipating, anti-diarrheal and anti-haemorrhoidal properties (Jayakumar and Geetha, 2012).

\section{PHARMACOLOGICAL PROPERTIES}

\section{Anticancer activity}

Essential oils isolated from leaves of wood apple shows antioxidant and cytotoxic activities. Thirugnanasampandan and David (2014) demonstrated that essential oil of $89.19 \mu \mathrm{g} / \mathrm{ml}$ inhibits human cancer cell line MCF-7 (Michigan Cancer Foundation-7) by DNA fragmentation. In the same ways Pradhan et al. (2012) evaluates antineoplastic activity of ethanolic extracts of fruits on human breast cancer cell lines (SRBR3 and MDA-MBA435) and found effective dose ED50 of 56.1 and $30.6 \mathrm{ig} / \mathrm{ml}$ respectively. Eluru et al. (2015) reveals the in vitro anti-tumor activity of methanolic extracts of fruits at oral dose of $570 \mathrm{mg} /$ $\mathrm{kg}$ body weight on mice model of Dalton's Ascitic Lymphoma (DAL) cell found that treatment with extract enhance nonviable cell counts in peritoneal exudates and decrease the viable cell count which may be because of absorption of extract by viable cells and the ultimate results was cell lysis by 
activation of macrophage or any type of cytokine production. The extract also restored RBC and hemoglobin content (Eluru et al., 2015). The anticancer property of the fruits is may be due to the presence of flavonoids (Ilango, and Chitra, 2009).

\section{Antidiabetic activity}

Anti-diabetic activity of $95 \%$ ethanolic extracts of unripe wood apple fruits was evaluated on streptozotocin-induced diabetic rats at $250 \mathrm{mg} / \mathrm{kg}$ body weight and found that it considerably lowers blood glucose levels of fasted, fed, and streptozotocin-induced diabetic rats (Gupta et al., 2009). Hypoglycemic effects are also observed on alloxan-induced diabetic rats. Methanolic extract at $1.75 \mathrm{~g} / \mathrm{kg}$ body weight is effective in prevention of hyperglycemia (Mishra and Garg, 2011). A 21 day trial of wood apple bark at dose of $200 \mathrm{mg} / \mathrm{kg}$ and $400 \mathrm{mg} / \mathrm{kg}$ body weight of methanolic extract reduces blood glucose level by $39 \%$ and $54.5 \%$ respectively (MohanaPriya et al., 2012). A similar effect was found by alloxan induced rat which was measured by blood serum levels (Ilango and Chitra, 2010). Anitha et al. (2015) also determined significant lowering of fasting and post prandial blood sugar level after consumption of fruit juice for 90 days.

\section{Antihyperlipidemic activity}

After administrating fruit powder at 2.5, 5 and $10 \mathrm{~g} / \mathrm{kg}$ body weight for 28 days reduces lipid profile, hepatic glucose-6-phosphatase, and significant increases hepatic glycogen, hexokinase and HDL. The presence of fibres, phytosterols, saponins, polyphenols, flavonoids and ascorbic acid may be responsible for that (Rupal et al., 2013).

\section{Antioxidant activities}

Antioxidant activity of wood apple pulp was determined by water, petroleum ether, chloroform, ethyl acetate, and methanol extracts by Priya Darsini et al. (2013). They conducted 2, 2-diphenyl1-picrylhydrazyl (DPPH) radical scavenging assay, trolox equivalent antioxidant capacity (TEAC) assay, hydroxyl radical scavenging assay (HRSA), ferric reducing antioxidant power (FRAP) assay, nitric oxide radical (NO) scavenging assay, and total antioxidant activity (TAA) and found marked antioxidant activity. In-vitro antioxidant activity of Petroleum ether, chloroform and methanolic extract of wood apple leaf was determined by DPPH radical scavenging activity, Nitric oxide radical scavenging activity and hydrogen peroxide scavenging activity method and reveals that all the extract possesses sufficient antioxidant property (Attarde, 2016). Similar activity was also reported by Kerkar et al. (2020) and Singhania et al. (2020). Methanolic extract was also effective in synergizing antioxidant enzymes such as superoxidase dismutase and catalase (Patel et al. 2012). A 30 days oral administration of ethanolic extract of leaf at $200 \mathrm{mg} / \mathrm{kg}$ body weight was effective in increasing activity of enzymatic antioxidants like Glutathione, superoxide dismutase (SOD), catalase (CAT) and peroxidase (Balamuruganvelu et al., 2015).

\section{Hepatoprotective activities}

Hepatoprotective activity of methanolic extracts of pulps was evaluated by Ilango and Chitra (2009) against carbon tetrachloride (CCl4)-induced liver damage in rats. They found that levels of hepatic enzymes especially aspartate transaminase (AST), alanine transaminase (ALT), alkaline phosphatase (AST), total protein (TP), total bilirubin (TB), and gamma glutamyltransferase (GGT) was increased and levels of super oxide dismutase (SOD), catalase (CAT), glutathione peroxidase (GPx), and glutathione (GSH) decreased by treatment of 100 , 200 and $400 \mathrm{mg} / \mathrm{kg}$ i.p. for 3 days in rats. In another study aqueous leaf extract raises serum alanine transaminase (ALT), aspartate aminotransferase (AST) and alkaline phosphatase (ALP) level. It also elevates urea, creatinine, potassium and sodium levels in the phenyl hydrazine-induced anemic nontreated rats compared to the normal control (Anacletus et al., 2019).

\section{Diuretic activity}

The methanolic extract of leaves has significantly increase urine output. The extent of urination and electrolyte excretion namely Sodium, potassium and chloride ions depend on extraction method. It was found that Microwave assisted extraction (MAE) has better activity as compared to Bath Sonicator extraction (BSE)(Parial et al., 2009). 


\section{Antiulcer and wound healing activities}

It was found that that wood apple fruit pulp is effective against indomethacin-induced gastric ulcer in rats. At $500 \mathrm{mg} / \mathrm{kg}$ it inhibits gastric ulceration by reducing gastric $\mathrm{HCl}$ concentration through increasing intra-gastric $\mathrm{pH}$ (Mishra et al., 2009). Wound healing activity of methanolic fruit extract increased by tightening wound-breaking strength, decreased epithelization period, increased wound contraction, and increased granulation tissue weight and hydroxyproline concentration at 400 $\mathrm{mg} / \mathrm{kg}$ of the extract (Ilango and Chitra, 2010). $L$. acidissima extracts significantly protect the gastric mucosa against ethanol induced injury by the reduction in the mucosal lesions on dose dependent manner. The phenolic compounds presents in the fruit is responsible for protection against ulcer on gastric wall and leucocytes infiltration of submucosal layers at $400 \mathrm{mg} / \mathrm{kg}$ leaf extract (Aneesha et al., 2018).

\section{Analgesic activity}

The analgesic activity was found against acetic acid- induced writhing mice and found $60.53 \%$ on methanol, $59.65 \%$ on acetone extracts of fruit peel as against $78.07 \%$ on standard drug Diclofenac $\mathrm{Na}$ (Islam et al., 2020).

\section{Neuroprotective activities}

Neuroprotective effects of wood apple was evaluated and showed that at $250 \mathrm{mg} / \mathrm{kg}$ and $500 \mathrm{mg} / \mathrm{kg}$ body weight it inhibits ischemia reperfusion-induced brain injury in rats (Rakhunde et al., 2014).

\section{Spermatotoxic activities}

Dhanapal et al. (2012) studied antispermatogenic activities of wood apple fruit pulp in adult male rats by treating with ethanolic extracts at 250 and $500 \mathrm{mg} / \mathrm{kg}$ for 55 days and reveals that they were responsible for decline in sperm count, motility and viability. They also increased proportion of abnormal sperm and reduce testicular protein content by $24.58 \%$ and $29.86 \%$, respectively.

\section{Antidiarrheal activity}

Senthilkumar et al. (2010) determined antidiarrhoeal and gastrointestinal motility reducing activity on aqueous bark extract of wood apple and found marked antidiarrheal activity by reducing average faeces weight and reduce GI motility (Senthilkumar et al., 2010). Similar data was found by Thomas method on castor oil-induced diarrhea at $500 \mathrm{mg} / \mathrm{kg}$ of methanol and acetone peel extracts and observed $47.13 \%$ and $44.83 \%$ inhibition (Islam et al., 2020).

\section{Antimicrobial activity}

The methanol and acetone fruit peels extract at $250 \mathrm{mg} / \mathrm{kg}$ shows moderate activity which inhibits $34.45 \%$ and $35.63 \%$ on Klebsiella Oxytoca, Vibrio metschnikovii, Escherichia coli, Bacillus subtilis and Staphylococcus aureus (Islam et al., 2020). The essential oil present on wood apple leaves containing $\beta$-pinene (28.4\%), Z-anethole (22.1\%), methyl chavicol $(12.0 \%)$, and E-anethole $(8.1 \%)$ which exerts antibacterial activity against five Gram-positive (Staphylococcus aureus, Micrococcus flavus, M. luteus, Bacillus subtilis, Streptococcus faecalis) and eight Gram-negative bacteria (Escherichia coli, Klebsiella pneumonia, Serratiamarcescens, Proteus mirabilis, P. vulgaris, Pseudomonas aeruginosa, Salmonella typhimurium, Enterobacteraerogenes), and four fungi (Aspergillusniger, A. fumigatus, Penicilliumchrysogenum, Candida albicans). The oils are also effective against Micrococcus luteus, Proteus mirabilis, Penicillium chrysogenum, and Aspergillus niger with minimum inhibitory concentration values of $0.31,0.52,0.20$, and 0.26 $\mathrm{mg} / \mathrm{ml}$, respectively (Joshi et al. 2011). Antibacterial activity was also assessed by agar well diffusion method against three gram positive bacteria (Staphylococcus aureus, Staphylococcus epidermidis, Bacillus subtilis) and a gram negative bacterium (Proteus mirabilis) (Pandey et al., 2014). The essential oils are present in different parts of the plant and provides antibacterial activity (Bagul et al., 2019). Minimum inhibitory concentration (MIC) was also determined by Naidu et al. (2014) on leaf extract in hexane, chloroform and methanol and show sufficient activities. Biosynthesized silver and zinc oxide nanoparticles was tested against Staphylococcus aureus, Bacillus cereus, Enterococcus faecalis, Escherichia coli, Salmonella typhi and Pseudomonas aeruginosa and found 
effectiveness (Patil and Taranath, 2018). Antimicrobial activity was also determined by well diffusion method against Escherichia coli, Salmonella typhi, Pseudomonas aeruginosa and Klebsiella pneumonia (Sonawane et al., 2018). There is another study of silver and zinc oxide nanoparticles on $S$. aureus, $S$. typhi and $P$. aeruginosa at $400 \mu \mathrm{g} / \mathrm{ml}$ and found maximum zone of inhibition 15.16, 15.5 and $13.33 / \mathrm{mm}$ respectively. Although zinc oxide Nano particles shows less activity as by comparison with silver Nano particles (Bheemanagouda et al., 2018). These Nano particles are also effective against $M$. tuberculosis at $12.5 \mathrm{ig} / \mathrm{ml}$ (Bheemanagouda et al., 2016). The wood apple is used traditionally in Thailand to treat oral and throat infection (Lairungruang et al., 2014). Pandey et al. (2014) evaluates antibacterial activity of dried pulp and rind at $500 \mathrm{mg} / \mathrm{ml}$ on Staphylococcus aureus, Staphylococcus, epidermidis, Bacillus subtilis and Proteus mirabilis. Other researchers are also reported antibacterial activity of wood apple (Panda et al., 2013; Momin et al., 2013 and Naidu et al., 2014).

\section{Anti-fungalactivity}

Pradhan et al. (2012) claims that fruit shells of wood apple has antifungal compounds such as psoralene, xanthotoxin, 2, 6-dimethoxy benzoquinone, and osthenol. Antifungal activity of leaf ethanolic extracts was done by cup plate techniques on $M$. gypseum, $T$. tonsurans, $T$. mentagrophytes, $C$. albicans and least $T$. rubrumon dose dependent manner (Shivakumar and Vidyasagar, 2015).

\section{Larvicidal activities}

Wood apple leaf is effective against larvae of Culexquinque fasciatus with $90 \%$ mortality at 3\% aqueous extract. The chloroform and methanol extract also shows $95 \%$ mortality at $100 \mathrm{ppm}$ concentration (Banerjee et al., 2011). Mosquitocidal activity was found due to the presence of terpene in wood apple leaf which inhibits eggs, larvae, and pupae of Aedesaegypti. The extracts have very good larvicidal and pupicidal activity (Reegan et al., 2014). Hexane extract of $L$. acidissima shows ovicidal activity $79.2 \%$ and $60 \%$ at $500 \mathrm{ppm}$ concentration against the eggs of Cx. quinquefasciatus and Ae. Aegypti (Reegan, et al., 2015).

\section{REFERENCES :}

Anacletus, F.C., Nwauche, K.T. and Ugwu, G.M. 2019. Hepatoprotective and nephroprotective potentials of aqueous leaves extract of Limonia acidissima in phenylhydrazineinduced anaemic wistar Rats. Asian J. Pharma. Res. Develop., 7(1):27-33.

Aneesha, A., Rao, R.N., Tejaswini, S.N., Durga, L.S.A., Haseena, S.K. and Maneesha, B. 2018. Phytochemical studies and anti-ulcer activity of Limonia acidissima linn. leaf in treating ethanol induced ulcer Albino rats. Indian J. Res. Pharm. Biotec., 6(3):104-110.

Anitha, S., Umadevi, S., Savita, H., Geetha, D. and Srinivas, K. 2015. Therapeutic effect of wood apple on hypertension and diabetes. Eco. Env. \& Cons., 21(2):1101-1106.

Asp, N.G. 1996. Dietary carbohydrates: Classification by chemistry and physiology. Food Chem., 57(1): 9-14.

Attarde. 2016. Attarde, D.L, Chaudhari, B.J. and Bhambar, R.S. 2011. Phytochemical investigation and in vitro antioxidant activity of extracts from leaves of Limonia acidissima linn. J Pharm Res., 4(3): 766-768

Bagul, V., Dhabekar, S.S., Sansarode, D. and Dandekar, S. 2019. Wood Apple (Limonia Acidissima L.): A multipurpose herb in cosmetics. Int. J. Sci. Dev. \& Res., 4(7):172181.

Balamuruganvelu, S., Abilash, S.C., Shree Lakshmidevi, S., Geethavani, B., Premlal KR., Jaikumar, S. and Sengottuvelu, S. 2015. AntioxidantActivity of Limonia acidissima in high fat diet induced hyperlipidemic rats. Int. J. Phytopharm., 6(4):181-183.

Banerjee, S., Singha, S., Laskar, S. and Chandra, G. 2011. Efficacy of Limonia acidissima L. (Rutaceae) leaf extract on larval immature of Culexquinquefasciatus Say 1823. Asian Pac. J. Trop. Med., 4:711-716.

Bheemanagouda, N., Patil, T.C. and Taranath. 2016. Limonia acidissima L. leaf mediated synthesis of zinc oxide nanoparticles: A potent tool against Mycobacterium tuberculosis. Int. J. Mycobacteriol., 5(2):197204. doi: 10.1016/j.ijmyco.2016.03.004. 
Bheemanagouda, N., Patil, T.C. and Taranath. 2018. Limonia acidissima L. leaf mediated synthesis of silver and zinc oxide nanoparticles and their antibacterial activities. Microb. Pathog., 115:227-232. doi: 10.1016/ j.micpath.2017.12.035.

Campous, D., Betalleluz, I., Tauquino, R., Chirinos, R. and Pedreschi, R. 2009. Nutritional and functional characterization of Andean chicuru (Stangearhizanta). Food Chem., 112(1):6370.

Dhanapal, R., Ratna, J.V., Sarathchandran, I. and Gupta, M. 2012. Reversible antispermatogenic and antisteroidogenic activities of Feronia limonia fruit pulp in adult male rats. Asian Pac. J. Trop. Biomed., 2:684-690.

Eluru, J.R., Taranalli, A.D. and Kawatra, S. 2015. Anti-tumour activity of Limonia acidissima L. methanolic extract in Mice Model of Dalton's Ascitic Lymphoma. Int. J. Pharmacogn. Phytochem.,7(6):1094-1100.

Gupta, R., Johri, S. and Saxena, A.M. 2009. Effect of ethanolic extract of Feronia elephantum Correa fruits on blood glucose levels in normal and streptozotocin-induced diabetic rats. Nat Prod Rad., 8:32-36.

Hiwale, S. 2015. Wood Apple (Feronia limonia Linn.). In: Sustainable Horticulture in Semiarid Dry Lands. Springer, New Delhi, doi.org/10.1007/978-81-322-2244-6_15.

Ilango, K. and Chitra, V. 2009. Hepatoprotective and antioxidant activities of fruit pulp of Limonia acidissima Linn. Int $J$ Health Res., 2:361-367.

Ilango, K. and Chitra, V. 2010. Wound healing and anti-oxidant activities of the fruit pulp of Limonia acidissima Linn (Rutaceae) in rats. Trop. J. Pharm. Res., 9:223-230.

Islam, F., Azad, A.K., Faysal, M., Azad, M.A.K., Islam, S., Amin, M.A. Nahida Sultana, Farhana Yeasmen Dola, Md. Mominur Rahman and Md. Zamshed Alam Begh. 2020. A Comparative Study of Analgesic, Antidiarrhoeal and Antimicrobial Activities of Methanol and Acetone Extracts of Fruits Peels of Limonia acidissima L. (Rutaceae). J. drug deliv. ther, 10(1-s):62-65. doi.org/ 10.22270/jddt.v10i1-s.3882
Jadeja, B.A. Odedra, N.K., Danger, N.R. and Baxi, U.S. 2005. Ethnomedicinal plants used by the people of Saurashtra to cure diarrhoea. Plant Arch., 5:381-392.

Jayakumar, A. and Geetha, K. 2012. Wood Apple: Uses and benefits. Market Survey, 24.

Jayashree, V.H. and Londonkar, R. 2014. Comparative phytochemical studies and antimicrobial potential of fruit extracts of Feronia limonia Linn. Int. J. Pharm. Pharm. Sci., 6(1):731-734.

Joshi, R.K., Badakar, V.M., Kholkute, S.D. and Khatib, N. 2011. Chemical composition and antimicrobial activity of the essential oil of the leaves of Feronia elephantum (Rutaceae) from Northwest Karnataka. Nat. Prod. Commun., 6:141-143.

Kerkar, S.P., Patil, S., Arya, S., Dabade, A. and Sonawane, S. 2020. Limonia acidissima: versatile and nutritional fruit of India. Int. J. Fruit Sci., S405-S413.

Kirtikar, K.R. and Basu, B.D. 1995. Feronia elephantum corr. Indian medicinal plants. 1: 496-498. India: L.M.B. Publishers.

Lairungruang, K., Itharat, A. and Panthong, S. 2014. Antimicrobial activity of extracts from a Thai traditional remedy called Kabpi for oral and throat infection and its plant components. J. Med. Assoc. Thai., 97(8):108115 .

Minal, P. and Sumitra, C. 2014. Development of quality control parameters for the standardization of Limonia acidissima $\mathrm{L}$. leaf and stem. Asian Pac. J. Trop. Med., S1:S244248. doi: 10.1016/S1995-7645(14)60240-6.

Mishra, A. and Garg, G.P. 2011. Antidiabetic activity of fruit pulp of Feronia elephantum Corr. Phcog J., 3(20):27-32.

Mishra, A., Arora, S., Gupta, R., Manvi, P.R.K. and Sharma, A.K. 2009. Effect of Feronia elephantum (Corr) fruit pulp extract on indomethacin-induced gastric ulcer in albino rats. Trop. J. Pharm. Res., 8:509-514.

Mohana-Priya, E., Gothandam, K.M. and Karthikeyan, S. 2012. Antidiabetic activity of Feronia limonia and Artocarpus heterophyllus in streptozotocin induced diabetic rats. Am. J. Food Technol., 7:43-49. 
Momin, M.A.M., Khan, M.R., Rayhan, J., Afrose, A., Rana, S. and Begum, AA. 2013. Evaluation of antibacterial and antidiarrhoeal activities of Feronia limonia Leaf Extract. Am. J. Plant Sci., 4:2181-2185.

Morton, J. 1987. Wood-Apple. In: Fruits of warm climates. 190-191.

Naidu, G.K., Sujatha, B. and Naidu, K.S. 2014. In vitro antibacterial activity analysis of leaves of Limonia acidissima. Not. Bot. Horti. Agrobot. Cluj. Napoca., 6:155-157.

Nithya, N. and Saraswathi, U. 2010. In vitro antioxidant and antibacterial efficacy of Feronia elephantum Correa fruit. Indian J. Nat. Prod. Res., 1:301-305.

Panda, N., Patro, V.J., Jena, B.K. and Panda, P.K. 2013. Evaluation of phytochemical and antimicrobial activity of ethanolic extract of Limonia acidissima L. Leaves. Int. J. Herb Med., 1: 22-27.

Pandey, S., Satpathy, G. and Gupta, R.K. 2014. Evaluation of nutritional, phytochemical, antioxidant and antibacterial activity of exotic fruit Limonia acidissima. J. Pharmacogn. Phytochem., 3(2):81-88.

Parial, S., Jain, D.C. and Joshi, S.B. 2009. Diuretic activity of the extracts of Limonia acidissima in rats. Rasayan J. Chem., 2:53-56.

Patel, D., Kumar, R., Laloo, D. and Hemalatha, S. 2012. Diabetes mellitus: an overview on its pharmacological aspects and reported medicinal plants having antidiabetic activity. Asian Pac. J. Trop. Biomed., 25: 411-420.

Patil, B. and Taranath, T. 2018. Limonia acidissima L. leaf mediated synthesis of silver and zinc oxide nanoparticles and their antibacterial activities. Microb. Pathog., 115: 227-232. doi: 10.1016/j.micpath.2017.12.035.

Pradhan, D., Tripathy, G. and Patanaik, S. 2012. Anticancer Activity of Limonia acidissima Linn (Rutaceae) Fruit extracts on human breast cancer cell lines. Trop. J. Pharm. Res., 11(3). doi: 10.4314/tjpr.v11i3.

Priya-Darsini, D.T., Maheshu, V., Vishnupriya, M., Nishaa. S. and Sasikumar, J.M. 2013. Antioxidant potential and amino acid analysis of underutilized tropical fruit Limonia acidissima L. Free RadicAntioxid., 3:62-69.
Rakhunde, P.B., Saher, S. and Ali, S.A. 2014. Neuroprotective effect of Feronia limonia on ischemia reperfusion induced brain injury in rats. Indian J. Pharm., 46:617-621.

Reegan, A.D., Gandhi, M.R., Paulraj, M.G. and Ignacimuthu, S. 2015. Ovicidal and oviposition deterrent activities of medicinal plant extracts against Aedes aegypti L. and Culex quinquefasciatus Say Mosquitoes (Diptera: Culicidae). Osong Public Health Res. Perspect., 6(1):64-69. doi: 10.1016/ j.phrp.2014.08.009.

Reegan, A.D., Gandhi, M.R., Paulraj, M.G., Balakrishna, K. and Ignacimuthu, S. 2014. Effect of niloticin, a protolimonoid isolated from Limonia acidissima L. (Rutaceae) on the immature stages of dengue vector Aedesaegypti L. (Diptera: Culicidae). Acta. Trop. 139:6, 7-76.

Rodrigues, S., Brito, E. and Silva, E. 2018. Wood Apple Limonia acidissima. Exotic Fruits, 443-446. doi: 10.1016/b978-0-12-8031384.00060-5.

Rupal, A., Amaravadi, V.R.L. and Narasimhacharya. 2013. Limonia fruit as a food supplement to regulate fluoride-induced hyperglycaemia and hyperlipidaemia. J. Sci. Food Agric., 93(2):422-426. doi: 10.1002/ jsfa.5762.

Sarwar, A.K.M.G. 2020. Medicinal and aromatic plant genetic resources of Bangladesh and their conservation at the Botanical Garden, Bangladesh Agricultural University. Int. J. Minor Fruits Med. Arom. Plants, 6(2):13-19.

Senthilkumar, K.L., Kumawat, B.K. and Rajkumar, M. 2010. Antidiarrhoeal activity of bark extracts of Limonia acidissima Linn. Res. J. Pharm. Biol. Chem. Sci., 1:550-553.

Shermin, S., Aktar, F., Ahsan, M. and Hasan, C.M. 2012. Antioxidant and cytotoxic activitiy of Limonia acidissima L. Dhaka Univ. J. Pharm. Sci.,11:75-77.

Shivakumar, P.S. and Vidyasagar, G.M. 2015. Antidermatophytic activity of ethanolic leaves extract of Limonia acidissima Groff. Int. Lett. Nat. Sci., 39: 56-62. 
Singhania, N., Kajla, P., Bishnoi, S., Barmanray, A. and R. 2020. Development and storage studies of wood apple (Limonia acidissima) chutney. Int. J. Chem. Stud., 8(1):2473-2476. doi: 10.22271/chemi.2020.v8.i1al.8639.

Sonawane, S., Bhagwat, A., and Arya, S. 2018. Limonia acidissima and Citrullus lanatus fruit seeds: Antimicrobial, thermal, structural, functional and protein identification study. Food Biosci., 26: 8-14. doi: 10.1016/ j.fbio.2018.09.001.

Thirugnanasampandan, R. and David, D. 2014. In vitro antioxidant and cytotoxic activities of essential oil of Feronia elephantum Correa. Asian Pac. J. Trop. Biomed., 4:290-293.
Vasant, R.A. and Narasimhacharyaa, A.V.R.L. 2011. Alleviation of fluoride-induced hepatic and renal oxidative stress in rats by the fruit of Limonia acidissima. Res. Rep. Fluoride., 44(1):14-20.

Vidhya, R. and Narain, A. 2011. Development of preserved products using under exploited fruit, wood apple (Limonia acidissima). Am. J. Food Technol., 6(4):279-288.

Vijayvargia, P. and Vijayvergia, R. 2014. A review on Limonia acidissima: Multi-potential medicinal plant. Int. J. Pharm. Sci. Rev. Res., 28:191-195.

Vijayvargia, P., Choudhary, S. and Vijayvergia, R. 2014. Preliminary phytochemical screening of Limonia acidissima Linn. Int. J. Pharm. Pharm. Sci., 6:134-136. 